\title{
GÊNERO, IDENTIDADE E PODER: UMA REFLEXÃO SOBRE VASTO MAR DE SARGAÇOS, DE J EAN RHYS
}

Shirley de Souza Gomes Carreira

\begin{abstract}
RESUMO
Este trabalho propóe uma análise do romance Vasto mar de sargaços, de Jean Rhys, no intuito de demonstrar como a autora desconstrói o discurso eurocêntrico de Charlotte Brontë em Jane Eyre, concedendo voz ao sujeito colonizado, além de permitir um "mergulho" na teia que o patriarcado teceu, aprisionando homens e mulheres em papéis sociais pré-determinados.
\end{abstract}

PALAVRAS-CHAVE: gênero, identidade, patriarcado

Because I, a mestiza,

Continually walk out of one culture

And into another,

Because I am all cultures at the same time,

alma entre dos mundos, tres, cuatro,

me zumba la cabeza con lo contradictorio

Estoy norteada por todas las voces que me hablan

Simultáneamente ${ }^{1}$

\section{Introdução}

m 2003, publiquei o artigo intitulado "A representação do outro em tempos de pós-colonialismo: uma poética de descolonização literária"2, em que abordava a questão do prefixo "pós” e suas implicaçôes na his-

1 Poema de Glória Anzaldúa: "Una Lucha de Fronteras".

ANZALDÚA, Gloria. Borderlands = La Frontera: The New Mestiza. San Francisco: Aunt Lute Books, 1999.

2 CARREIRA, Shirley. A representação do outro em tempos de pós-colonialismo: uma poética de descolonização literária. Revista Eletrônica do Instituto de Humanidades. V.2, n.6, Julho-Setembro de 2003, p.1. 
tória recente das nações que conquistaram sua independência após um longo período de dominação política e cultural.

Meu questionamento, entáo, dizia respeito ao fato de que admitir um estado pós-colonial é, consequentemente, pressupor que o colonialismo teve um fim, quando os fatos históricos nos mostram que ele continua vivo não só nos países outrora colonizados, mas persiste também na proposta de globalização, cuja forma de domínio se esconde sob a ideia de uma aparente igualdade.

Defendia também um processo de descolonização cultural e literária, que, segundo Armando Gnisci ${ }^{3}$, deveria começar pela auscultação de vozes que se insurgem, advindas das margens, e falam de experiências particulares e diversas, sob um ponto de vista que busca aliar a tradição à tradução, fugindo às visóes exóticas e folclóricas encenadas pelo olhar hegemônico.

No século XX, foram muitas as tentativas de ceder a voz a esse Outro, marginalizado e silenciado pela afasia histórica, por meio do descentramento do lugar de fala. Coube, também, à literatura um papel de vulto nesse processo, na medida em que a representação da alteridade perdia o caráter assimétrico que sempre a caracterizou.

Uma das estratégias literárias para a concretização da descentralização foi a reescritura de obras canônicas em que o sujeito colonizado era representado em sua condição de subalternidade, a fim de dar-lhes nova roupagem e reinterpretá-las à luz da concepção contemporânea de identidade.

Este trabalho propóe uma análise do romance Vasto mar de sargaços ${ }^{4}$, de Jean Rhys, no intuito de demonstrar como a autora desconstrói o discurso eurocêntrico, concedendo voz ao sujeito colonizado, além de permitir um "mergulho" na teia que o patriarcado teceu, aprisionando homens e mulheres em papéis sociais pré-determinados.

Ao mesmo tempo em que oferece uma releitura do romance Jane Eyre de Charlotte Brontë, em uma perspectiva que, segundo alguns críticos, pode ser considerada como um "acerto de contas" com o colonialismo e o patriarcado, indubitavelmente, o romance de Rhys demonstra como o sistema pa-

3 GNISCI, Armando. A descolonização que não passa. Trad. Shirley de Souza Gomes Carreira. Revista Eletrônica do Instituto de Humanidades, v2. N. 6, jul.-set. 2003.

4 A tradução portuguesa será utilizada nesta análise do romance.

RHYS, Jean. Vasto mar de sargaços. Lisboa: Bertrand, 2009.

5 BRONTË, Charlotte. Jane Eyre. London: Penguin Classics, 1994. 
triarcal não só impunha à mulher um papel de subalternidade, mas também imputava ao homem obrigaçôes tais que também cerceavam a sua independência e liberdade.

Esta afirmação pode suscitar reações, uma vez que parece atenuar, de certo modo, a gravidade da atuação masculina no que diz respeito à subjugação das mulheres. Na verdade, parto de uma visão pautada exclusivamente na différance, que nos impede de, com base em uma perspectiva excessivamente dualista, continuar a refletir sobre o mundo que nos cerca em termos de visóes binárias do comportamento social ou incorrer em um procedimento que, segundo Leyla Perrone-Moisés ${ }^{6}$, se resume ao cultivo de uma hostilidade vingativa ao masculino.

\section{Homens e mulheres: papéis sociais e releituras do passado literário e histórico}

O patriarcado não designa o poder do pai, mas o poder dos homens, ou do masculino, enquanto categoria social. É uma forma de organização social na qual as relaçóes são regidas por dois princípios básicos: a subordinação hierárquica das mulheres aos homens e a subordinação hierárquica dos jovens aos homens mais velhos.

Sedimentado na diferença biológica entre os sexos, o patriarcado projetou as características que constituem a identidade do homem e da mulher em um contexto social, beneficiando-se de um imaginário que vincula força física e poder, atribuindo ao masculino a ideia de superioridade e, em contrapartida, ao feminino o sentido de fraqueza.

A supremacia masculina, ditada pelos valores do patriarcado, legitimou o controle da sexualidade, dos corpos e da autonomia feminina, e estabeleceu papéis sexuais e sociais nos quais o masculino tem vantagens e prerrogativas ${ }^{7}$.

O pensamento patriarcal tradicional configura o poder do pai na família como origem e modelo de todas as relaçóes de poder e autoridade, que vigo-

6 PERRONE-MOISÉS, Leila. Vira e mexe nacionalismo: paradoxos do nacionalismo literário. São Paulo: Companhia das Letras , 2007, p. 169.

7 MILLET, K. Sexual politics. New York: Doubleday \& Company, 1970.

SCOTT, J. Gênero: uma categoria útil de análise histórica. Educação \& Realidade, 20, 71-99, Porto Alegre, 1995. 
raram até o século XVII, quando o direito do pai sobre a mulher na sociedade civil foi substituído pelo direito natural conjugal dos homens sobre as mulheres; como se cada homem tivesse o direito natural de poder sobre a esposa, constituindo um patriarcado moderno ${ }^{8}$.

A subversão da construção social da mulher segundo a ótica do patriarcado teve a sua origem em múltiplas esferas da vida social e é inegável o papel da literatura nesse processo. No caso específico de Jane Eyre, têm sido inúmeras as leituras críticas do romance, que transformam Bertha Mason - a louca do sótão - em um alvo das discussóes sobre o feminismo?.

\subsection{A ficção sobre a ficção: reinterpretações}

Jean Rhys vivenciou as agruras da exclusão causada por questóes raciais. Caribenha, filha de um galês com uma crioula ${ }^{10}$ de origem escocesa, ela se sentia, desde a infância, socialmente deslocada, pois, em sua ilha natal, Dominica, não encontrava aceitação por parte de nenhum dos grupamentos sociais existentes, crioulo ou europeu. Assim, foi para Londres ainda muito jovem e, na tentativa de encontrar o seu lugar, experimentou o deslocamento absoluto, físico e social, além da pobreza extrema. Creem os críticos ${ }^{11}$ que sua história pessoal foi a mola propulsora para a sua concepção de Bertha, a personagem originalmente criada por Brontë.

Em Jane Eyre, Bertha é uma jamaicana, mulher de Edward Rochester, que, louca, vive trancada em um sótão. No romance, o diagnóstico do Dr. Carter comprova que a miscigenação, acrescida da fragilidade feminina e da libido exacerbada, levou Bertha à loucura. Segundo a visão do médico, o fato dos negros náo pertencerem ao Homo sapiens fez com que ela desenvolvesse uma incompatibilidade genética degenerativa, acelerada pela depravação e

8 PATEMAN, C. O contrato sexual. Rio: Paz e Terra, 1993, p. 167.

9 BUITENDAG, Hanrie. The 'Creature' in the Attic: The Function and Metamorphoses of Brontës Bertha within Feminist discourse. 2006. Disponível em:

http://sun025.sun.ac.za/portal/page/portal/Arts/Departments/english/Documents/Hanrie\%20Buitendag.pdf Acesso em 12 de dezembro de 2011.

10 Branca de origem mestiça.

11 GILBERT, Sandra M. and GUBAR, Susan. Eds. The Madwoman in the Attic: The Woman Writer and the Nineteenth-Century Imagination. New Haven, CT: Yale University Press, reprint edition 2000 . 
pela histeria materna. Antes de enlouquecer, Bertha era bela e parecia branca, e após sofrer da loucura degenerativa, surge negra, feia e arroxeada.

Essa concepção deriva não apenas do desconhecimento, que persistiu até o fim do século XIX, de que os genes e cromossomos do feto são definidos na fecundação ${ }^{12}$, como também da concepção de que a mistura de brancos com não brancos poderia provocar terríveis consequências à população mundial ${ }^{13}$. O fato é que, a partir da conquista das Américas, África e Ásia, o europeu passou a cientificar mitos convenientes à prática escravista e colonizadora.

Ao fazer de Jane a sua heroína, construindo-a como uma mulher capaz de sobreviver do próprio trabalho em uma época em que a mulher era totalmente dependente do homem, Brontë lhe confere um certo tom feminista, embora não deixe de focalizar a realização feminina por meio do amor e do casamento. Assim, no capítulo 38, ela escapa à relação amorosa assimétrica, afirmando: "I am my husband's life as fully as he is mine... To be together is for us to be at once as free as in solitude, as gay as in company... We are precisely suited in character-perfect concord is the result"14.

Nesse contexto, Bertha tem um papel diferenciado. De obstáculo à realização amorosa da protagonista, ela passa a ser alvo de múltiplas interpretações: a personificação do colonizado, cuja cultura é aprisionada pelo colonizador; uma representação simbólica da condição social da mulher vitoriana; e até mesmo uma expressão da rejeição inconsciente de Jane à opressão do sistema patriarcal.

No romance de Rhys, Vasto mar de sargaços, Antoinette Cosway aparece como uma nova versão de Bertha Mason. Ao contrário do que acontece no texto de Brontë, a mulher caribenha desponta, entre os demais personagens, bela e glamorosa, tornando-se a monstruosa Bertha quase no fim da narrativa.

Jean Rhys sempre rejeitou a visão de Bertha conforme apresentada em Jane Eyre, ou seja, enquanto mulher colonial bestializada em função da mestiçagem. Assim, ela lhe confere uma identidade construída por meio do distanciamento do olhar colonizador, narrando a sua história em um período anterior ao da narrativa de Brontë.

12 ZACK, Naomi. Philosophy of Science and Race. New York: Routledge, 2002, p. 64-5.

13 KANT, Immanuel. [1764].Observations on the Feeling of the Beautiful and Sublime. Berkeley: University of California Press, 1996, p. 16.

14 BRONTË, Charlotte. Jane Eyre. London: Penguin Classics, 1994. 
Essa revisão do hipotexto, sob a ótica do colonizado, implica também uma estrutura narrativa diferenciada, baseada na polifonia, que objetiva claramente à narrativa dos fatos sob diferentes pontos de vista: de Antoinette, de seu marido, Rochester, da criadagem etc.

A história se passa na Jamaica, onde nasce Antoinette, filha de Annette Cosway, jovem quase branca, oriunda de uma família abastada da Martinica e esposa do impiedoso escravocrata mestiço Sr. Cosway, que morre deixando a família empobrecida. Em criança, ela brinca com os filhos de ex-escravos, cria laços de amizade com a negra Christophine, ama-seca e mucama da família, e não compreende a dimensão da questão racial no mundo em que vive até que, com a morte do pai, a hostilidade da comunidade local começa a manifestar-se.

Quando sua mãe torna a se casar, desta vez com Mr. Mason, um inglês que restaura a condição financeira da família, Antoinette se defronta pela primeira vez com a importância social da raça. Sua mãe esforça-se para esconder qualquer traço de miscigenação. A política do branqueamento lhe é imposta, assim como o casamento com um inglês. Suas feições lhe permitem passar por branca genuína e esconder a origem creole.

A releitura que Jean Rhys promove em Vasto mar de sargaços consiste em uma reelaboração intertextual da personagem de Brontë como uma resposta ao colonialismo e ao patriarcado, mas deixa, igualmente, entrever os impasses causados pelo sistema naqueles que detinham o poder nas relaçóes sociais, ou seja, nos homens.

A perspectiva masculina instaurada na segunda parte do romance abre espaço para a representação de um Rochester inseguro e pleno de dúvidas, atemorizado com a cultura e os costumes de uma terra que se revela estranha, bem como receoso do poder de sedução da mulher que tomara como esposa.

Tal receio manifesta-se cedo, logo após o casamento: "Essa mulher é uma estranha. (...) Não a comprei, ela é que me comprou, ou é o que ela pensa”"15.

Ao mesmo tempo em que a inicia nas artes do sexo, fazendo-a apaixonar-se por ele, Rochester tem consciência do desejo avassalador que Antoinette lhe provoca.

15 RHYS, Jean. Vasto mar de sargaços. op. cit., p. 65. 
Eu a vi morrer tantas vezes. Do meu modo, não no dela. À luz do sol, na sombra, ao luar, à luz das velas. Nas longas tardes quando a casa estava vazia. Somente o sol estava lá para nos fazer companhia. A gente expulsava-o. E por que não? Depressa ela se tornou tão ávida para aquilo a que se chama amar como eu. ${ }^{16}$

Logo, ele faz do desejo que ela sente por ele um meio de reafirmação. Aquilo que o atormentava, o possível domínio que ela poderia vir a ter sobre ele, passa a ser o seu instrumento para submetê-la; para o exercício do seu poder.

Preso aos conceitos do mundo dualista em que fora criado, Rochester não estava preparado para enfrentar as diferenças e, muito menos, o poder de atração de uma mulher com quem se casara apenas para obedecer à vontade do pai:

Querido pai. As trinta mil libras foram-me pagas sem perguntas nem condiçôes. Nenhuma quantia prevista para ela (isso tem também de ser visto). Tenho agora um modesto rendimento. Nunca mais serei um fardo para ti ou para o meu querido irmão, o filho que tu amas. Acabaram-se as cartas a mendigar, os pedidos de dinheiro. Nenhuma das manobras furtivas de um filho mais novo. Vendi a minha alma ou vendeste-a tu, e afinal será assim um negócio tão mal? Dizem que a rapariga é belíssima. Ela é belíssima. Porém... ${ }^{17}$

Ao ser enviado pelo pai para o casamento com Antoinette, Rochester se sente uma presa do seu papel social. $\mathrm{Na}$ véspera do casamento, quando Richard, o irmão de Antoinette, lhe diz que ela não quer casar-se com ele, Rochester se vê diante da possibilidade de desconstrução do poder que cabe ao homem na sociedade patriarcal. Ao conversar com a noiva, buscando demovê-la de sua decisão, é no seu papel que pensa; é o seu papel que ele defende. Naquele contexto, todas as relaçôes resumiam-se à questão do poder, pois "não

\footnotetext{
16 Idem, p. 86.

17 Idem, p. 66.
} 
tinha nenhuma vontade de regressar a Inglaterra na pele de um pretendente rejeitado por aquela rapariga crioula" 18 .

A carta de Daniel Cosway a Rochester acaba por concretizar diante de seus olhos os receios que trazia dentro de si. Daniel alerta-o para o fato de que a mestiçagem, segundo a crença da época, estava associada à loucura, e que a mãe de Antoinette morrera louca. Além disso, era visível a todos o fascínio que ela exercia sobre Rochester:

Ouço dizer que o senhor é jovem e belo, com uma palavra amável para todos, negros, brancos, mestiços também. Mas ouço também que a rapariga é linda como a mãe era linda, e que o senhor está enfeitiçado por ela. Ela entrou no seu sangue e nos seus ossos. De noite e de dia. Mas o senhor, como homem de respeito, sabe bem que para o casamento é necessário algo mais que tudo isso. ${ }^{19}$

Ao renomear Antoinette, chamando-a Bertha, Rochester constrói uma mulher a quem pode manipular com mais facilidade. Rhys faz com que Antoinette se dê conta disso: “- Eu não me chamo Bertha. Estás a tentar fazer de mim outra pessoa qualquer, chamando-me por outro nome. Eu sei, isso também é macumba" ${ }^{20}$. Aos poucos, Rochester transfigura Antoinette, pois Bertha não se assemelha à "criatura pálida e silenciosa com quem tinha casado"21.

No entanto, os artifícios de Rochester para não sucumbir ao fascínio de Antoinette não escapam a Christophine, a empregada da Martinica:

Não sei tudo o que o senhor fez, mas sei algumas coisas. Toda a gente sabe que o senhor casou com ela por causa do dinheiro dela, e que ficou com tudo. E entâo quer dar cabo dela, porque tem ciúmes dela. Ela é mais melhor do que o senhor, ela tem melhor sangue dentro dela e não se importa com dinheiro; para ela não vale nada. Oh, eu vi isso à primeira vez que olhei para

\footnotetext{
18 Idem, p. 73.

19 Idem, p. 91.

20 Idem, p. 134.

21 Idem, p. 82.
} 
o senhor. O senhor jovem mas já endurecido. O senhor está a enganar a rapariga. Fá-la pensar que o senhor não consegue ver o Sol por olhar para ela.

Era isso mesmo, pensei eu. ${ }^{22}$

Rochester aprendera a desempenhar o seu papel muito cedo: “Que idade tinha quando aprendi a esconder o que sentia? Era ainda um rapazinho muito pequeno. Seis, cinco, talvez antes. Era necessário, haviam-me dito, e sempre tinha aceite essa maneira de ver" 23 . A sua relação com o mundo do patriarcado era de subserviência, de aceitação de algo que intimamente rejeitava.

A fala de Rochester em Vasto mar de sargaços é a de um homem recalcado por sentir-se preterido em sua relação com o pai, inseguro por não se sentir capaz de adequar-se ao papel que lhe destinam, instável por não ter vontade própria. É na esposa que ele projeta todo o seu ressentimento.

Antoinette também havia sido educada para ocultar suas raízes creole. Quando Coulibri é queimada pelos negros, ela faz uma tentativa de tornar às suas origens, buscando refúgio em Tia, companheira de folguedos desde a infância, mas a pedrada que recebe demonstra que o seu lugar não é entre os negros. Para ser aceita pelos brancos, teria de renegar as origens, aceitar os códigos do passing, do "branqueamento", e isso significava comportar-se como uma mulher inglesa. Esse é o motivo que a leva ao casamento com Rochester: uma tentativa de aceitação.

As identidades de ambos são construídas sob a égide do patriarcado. A par do visível choque entre culturas, que Rhys retrata a partir das reaçóes de Rochester aos hábitos e crenças locais, há a representação da relação entre gêneros.

Se por um lado é clara a atitude de Rochester ao imbuir-se da figura do opressor masculino, representante do colonizador; curiosamente, por outro, Rhys constrói, ao longo do romance, um somatório de reflexóes e reaçóes do personagem que levam o leitor a compreender que Rochester, assim como Antoinette, não se sente plenamente confortável em seu papel social.

22 Idem, p. 139.
23 Idem, p. 95. 
Tudo refulgia de cores brilhantes, estranhíssimas, mas que nada significavam para mim. Nem sequer ela, a rapariga com quem ia casar. Quando finalmente a encontrei, curvei-me, sorri, beijei-lhe a mão, dancei com ela. Desempenhei o papel que esperavam que eu desempenhasse. Ela nunca teve absolutamente nada a ver comigo. Qualquer movimento que fizesse era um esforço da vontade, e por vezes surpreendia-me que ninguém se apercebesse disso. Punha-me à escuta da minha própria voz e maravilhava-me com ela, calma, correcta mas sem qualquer vibração. Mas devo ter tido um desempenho impecável. Se vi uma expressão de dúvida ou curiosidade foi num rosto negro, não num rosto branco. ${ }^{24}$

Antoinette não esperava vir a apaixonar-se pelo marido e ele não esperava ter sentimentos tão contraditórios em relação a ela: "Quanto à felicidade que eu lhe dava, isso era pior que nada. Eu não a amava. Tinha ânsia dela, mas isso não é amor. Sentia muito pouca ternura por ela, ela era para mim uma estranha, uma estranha que não pensava e sentia como eu." 25

É clara a contradição entre a atração que Rochester sente por Antoinette e a sua rejeição em relação a ela e ao mundo que ela representa. Assim, ele reage à forma carinhosa com que a mulher trata Christophine, ao medo que sente dos encantamentos e dos zombies.

Por outro lado, Antoinette percebe que, embora apaixonada pelo marido, não consegue evitar que ele se distancie dela e pede a Christophine que a ajude a trazê-lo de volta com uma poção obeah. Esta a adverte que esses encantamentos não funcionam com "békés" ${ }^{26}$, mas concorda. Essa passagem ilustra claramente a condição de Antoinette: uma mulher que vive entre dois mundos, sem pertencer a nenhum deles ${ }^{27}$.

Em conversa com Rochester, Christophine assim define a condição de Antoinette: "Ela não é béké como o senhor, mas ela é béké, e também não

24 Idem, p. 71.

25 Idem, p. 87.

26 Blanc Créole, abreviado para BK (béké).

27 EMERY, Mary Lou. Jean Rhys at "World's End": Novels of Colonial and Sexual exile. Austin: University of Texas Press, 1990, p. 4. 
como nós." ${ }^{28}$ A cor da pele de Antoinette impede a poção de funcionar, porém não a torna imune à tática de Rochester para subjugá-la: a troca de nomes.

A questáo dos nomes vai além do processo de anulação da subjetividade de Antoinette. Rochester só é assim identificado por aqueles leitores que conhecem o romance de Brontë, pois, em Vasto mar de sargaços, ele permanece anônimo até o fim. O fato de "aquele que não tem nome" ser quem tem o poder para nomear reforça o papel de dominador, que ele assume quando decide infligir à mulher um castigo maior do que o abandono.

A revelação de que Antoinette pertencera a outro homem é a gota d'água. A impetuosidade sexual de sua esposa, que lhe causa tantos sentimentos controvertidos, de atração e repulsa, leva-o a supor que todos sabiam que ela já tivera relacionamentos com outros homens. "Enquanto caminhava recordava-me do rosto do meu pai e dos seus lábios finos, dos olhos redondos e convencidos do meu irmão. Eles sabiam. E Richard, esse idiota, sabia também. E a rapariga com seu rosto inexpressivo e sorridente. Todos eles sabiam." ${ }^{29}$

A tentativa fracassada do encantamento, a forma como se entregam um ao outro e o despudor com que ela o trata acabam por desencadear um sentimento de ódio em Rochester que só seria possível aplacar se imputasse a Antoinette uma dor equivalente à que sentia. Ao relacionar-se sexualmente com a criada Amélie na manhã seguinte, sabendo que sua mulher o ouvirá do outro lado do tabique que separa os aposentos, ele começa a pôr em prática a sua vingança.

Mesmo mediante a tentativa de argumentação de Christophine - que nunca se deixara enganar por ele -, Rochester torna-se implacável:

Criatura vazia, tola. Feita para amar? Sim, mas não terá amante nenhum, porque eu não a quero e ela não verá nenhum outro. (...) Ela disse que adorava este lugar. Há-de vê-lo agora pela última vez. Procurarei ver nela uma lágrima, uma lágrima humana. Não essa face odiosa e vazia de lunática. Escutarei... se ela disser adeus, talvez adieu. (...) Se ela também o diz, ou chora, tomá-la-ei nos braços, à minha doida. Ela é louca mas

\footnotetext{
28 RHYS, Jean. Vasto mar de sargaços. op. cit., p. 141. 
minha, minha. Que me importarão os deuses ou os demônios ou o próprio Destino? Se ela sorri ou chora ou ambas as coisas? Para mim..$^{30}$

A contradição que permeia os sentimentos de Rochester é perceptível nas passagens a seguir:

Odiava as montanhas e as colinas, os rios e a chuva. Odiava o pôr do Sol fosse de que cor fosse, odiava a sua beleza e magia e o segredo que nunca eu descobriria. Odiava a sua indiferença e crueldade, que era parte do seu encanto. Acima de tudo odiava-a a ela. Pois pertencia à magia e ao encanto. Ela tinha-me deixado sequioso, e toda a minha vida seria sede e saudade do que eu tinha perdido antes de o ter encontrado. ${ }^{31}$

Eles compraram-me, a mim, com o teu mesquinho dinheiro. Tu ajudaste-os a fazê-lo. Tu decepcionaste-me, traíste-me, e farás pior ainda se tiveres oportunidade (...) Se eu estou destinado ao inferno, deixá-lo vir o inferno. Falsos paraísos nunca mais. Nunca mais a maldita magia. Tu odeias-me e eu odeio-te. Veremos quem odeia melhor. ${ }^{32}$

Em meio a esse turbilhão de sentimentos desconexos, Rochester engendra o seu plano de isolar Antoinette até que ela se torne "apenas uma recordação a evitar, bem fechada, e como todas as recordaçóes apenas uma lenda. $\mathrm{Ou}$ uma mentira..." 33

\section{Gênero, identidade e poder}

The sex-gender system, in short, is both a sociocultural construct and a semiotic apparatus, a system of representation whi-

\footnotetext{
30 Idem, p. 151.

31 Idem, p. 157.

32 Idem, p. 155.

33 Idem, p. 157.
} 
ch assigns meaning (identity, value, prestige, location in kindship, status in the social hierarchy, etc.) to individuals within a society. [...] The construction of gender is both the product and the process of its representation. ${ }^{34}$

A leitura de Vasto mar de sargaços permite interpretar o aprisionamento de Bertha no sótão como o meio que Rochester encontra de subjugar nela o que o assusta em si mesmo.

A configuração de Antoinette enquanto personagem faz-nos compreender que, ao invés de buscar a igualdade, "sameness", ela deseja apenas a aceitação das diferenças. Assim, qualquer tentativa de interpretar o romance como puro embate entre os sexos, ou mesmo entre colonizador e colonizado, falharia em captar as nuances que Rhys impóe às personagens. Muito embora a autora focalize a estrutura social do patriarcado como detentora de um poder destrutivo no que diz respeito à individuação, à identidade, o romance não reproduz em sua essência as concepções binárias a ele associadas.

A proposta, assim, é lê-lo à luz do conceito derridiano de différance, não como uma luta entre gêneros, mas como uma representação da relação diferencial entre identidades que foram igualmente afetadas pelas normas da sociedade patriarcal, acrescidos aí os dilemas oriundos das diferenças de classe e das questóes raciais.

À medida que cria para a louca do sótão de Jane Eyre uma história que faça dela mais que uma criatura subumana, Rhys imputa à personagem possíveis causas para essa loucura: o sentimento de inadequação social, a carência afetiva, a indefinição identitária.

Se em sua infância o fato de ser mestiça a fez sempre sentir-se como alguém que não pertence a lugar nenhum, em sua juventude, a carência afetiva faz com que busque a aceitação social via matrimônio com um inglês. É também a questão da afetividade que norteia a sua entrega aos prazeres sensuais que, mais tarde, serviráo de argumento para que o marido a julgue devassa e socialmente inaceitável.

34 DE LAURETIS, Teresa. Tecnologies of Gender. Bloomington: Indiana University Press, 1987, p. 5. 
O senhor quer o dinheiro dela mas não a quer a ela. Está a pensar fingir que ela está louca. Eu sei. Os médicos dizem o que o senhor lhes disser para dizerem. Esse homem, Richard, ele diz o que o senhor quer que ele diga...contente e de acordo com tudo, eu sei. Ela será como a mãe dela. ${ }^{35}$

$\mathrm{Na}$ realidade, a histerização do corpo feminino, como nos lembra Foucault $^{36}$, fazia parte de uma rede de vetores situados historicamente a partir do século XVIII cuja finalidade última era o exercício do poder. Foi essa a visão que norteou a concepção da Bertha criada por Brontë.

Quando Rochester desenha uma casa inglesa e, em um dos quartos, uma mulher de pé, antecipando o seu plano de confinar Antoinette, silenciando-a, ele reafirma o seu poder sobre ela. É o seu modo de vingar-se de uma outra forma de poder da qual ele próprio havia sido vítima:

Agora sei que planeaste isto porque te querias ver livre de mim. Não tinhas por mim qualquer amor. E o meu irmão também não tinha. $\mathrm{O}$ teu plano resultou porque eu era jovem, convencido, tolo, confiante. Acima de tudo porque era jovem. Foste capaz de fazer isto comigo... ${ }^{37}$

Silenciar é um não-dizer histórico e ideológico, pois depende da posição do sujeito que fala. Há um inter-relacionamento significativo entre o silenciado, a memória e o esquecimento ${ }^{38}$. Através do instrumento do silenciamento, emudece-se a memória do subalterno. Impede-se a expressão da sua revolta. Apaga-se a chama da sua individualidade. O silêncio permite gritar mais alto o discurso etnocêntrico, homogeneizador e monolítico que se quer único e verdadeiro, boicotando movimentos que tentam recuperar memórias sufocadas.

Quando Rochester, por meio do confinamento, impóe a Bertha / Antoinette um silêncio que visa ao apagamento, à extinção da memória, ele também

35 RHYS, Jean. Vasto mar de sargaços. op cit., p. 146.

36 FOUCAULT, Michel. História da Sexualidade: A Vontade de Saber. 7 ed. Rio de Janeiro: Graal, 1994, p. 27.

37 Idem, p. 147.

38 POLLAK, Michael. Estudos Históricos, Rio de Janeiro, vol. 2, n. 3, 1989, p. 3-15. 
quer apagar da própria lembrança os fatos de sua vida que o incomodam. É o seu passe para assumir definitivamente o papel que lhe fora destinado pelo patriarcado.

Assim, dois indivíduos que compartilham a mesma sensação de impropriedade, de inadequação, embora por razóes diversas, acabam por concretizar a relação binária e assimétrica ditada pelo patriarcado, incapazes de sobreviver ao reconhecimento e à aceitação de suas diferenças culturais e sociais.

\section{Considerações finais: a literatura como lugar de fala}

Muito embora a história narrada em Vasto mar de sargaços se passe em 1833, um pouco antes do que a narrativa de Brontë em Jane Eyre, que se inicia em 1847, pode-se entrever no modo em que o romance foi engendrado o ímpeto da autora em trazer à tona questóes que não se extinguiram com a independência política.

Voltamos, aqui, à implicação do prefixo "pós" quando usado em relação às ex-colônias. No caso específico do Caribe, os longos anos de escravidão e dedicação à agricultura, não possibilitaram à população caribenha encontrar de imediato um caminho para aquilo que Gnisci denomina "descolonização cultural". Assim, pode-se dizer que Rhys "sentiu na pele" o peso da sua origem quando, vivendo na Inglaterra, tentou se libertar das amarras da sua condição de mulher caribenha, defrontando-se com o preconceito.

Vasto mar de sargaços é efetivamente uma tentativa de desconstrução da visão eurocêntrica de Brontë, na medida em que desfaz a concepção de Bertha como uma mulher louca, de feiçóes animalescas, ora até comparada a um vampiro, cuja existência em Jane Eyre parece apenas ser a de um drástico contraste para enfatizar as qualidades da heroína. Recriando-a, conferindo-lhe um nome diferente, concedendo-lhe uma história, Jean Rhys dá-lhe voz: uma voz que busca insurgir-se e ser ouvida.

A literatura é entâo a arena onde ocorre o embate entre dois discursos: o de Rochester e o de Antoinette. Se em Jane Eyre a existência de Bertha depende do discurso de Jane, a heroína, no romance de Rhys a história pode ser observada por diferentes prismas. Justamente na ótica diferenciada dos narradores, a autora demonstra que o lado mais perverso do patriarcado é a forma como ele subjuga homens e mulheres atando-os aos seus papéis sociais, 
transformando a relação homem-mulher em uma reprodução de outra relação binária: a que se dá entre algoz e vítima.

Importa, no entanto, lembrar que, na primeira parte de Vasto mar de sargaços, é a voz de Antoinette que expressa a sua dificuldade de definir o seu lugar no mundo. Após a aceitação do matrimônio com Rochester, quando ela gradualmente se apaixona por ele, essas questôes ficam momentaneamente em segundo plano. A princípio, parece-lhe possível a convivência entre as suas diferenças, até mesmo porque Rochester mostra-se inseguro, dividido pela atração e a repulsa que aquele mundo, novo para ele, lhe suscita. Essa insegurança do marido assemelha-se à sua própria, aproximando-os a tal ponto que Rochester pensa, inclusive, em dar-lhe uma parte dos bens que recebeu como dote, o que definitivamente não acontece ao final.

A liberdade com que Antoinette expressa sua vontade e concretiza seus desejos faz com que o lado imaturo e indeciso de Rochester se sinta ameaçado, porque lhe faz lembrar a própria subserviência à vontade do pai, a sua incapacidade de escolher o próprio destino. O Rochester impiedoso, vingativo, capaz de aprisionar Antoinette, sentenciando-a ao isolamento e ao silêncio, é um dos produtos do patriarcado, da falsa moral do século XIX, e, principalmente, da necessidade de reproduzir continuamente os modelos responsáveis pela hegemonia do império.

A poção preparada por Christophine é, na realidade, uma metáfora para a ameaça da perda do controle e da "inglesidade", fazendo com que Rochester passe a disciplinar-se e a assumir a identidade à qual até então estivera frouxamente atado.

Rhys é bem sucedida ao narrar como os papéis sociais determinados pela sociedade patriarcal são engendrados, assim como elabora um passado bastante convincente para a Bertha de Jane Eyre. No entanto, Antoinette não pode ser compreendida como o Outro que desafia a hegemonia do império, ou mesmo do patriarcado; pois, se Rochester estivesse igualmente apaixonado por ela, a sua aceitação do modelo hegemônico seria completa. Ela aceitaria de bom grado a representação social do papel da esposa inglesa. Indubitavelmente o maior mérito do romance, a par da primorosa narrativa e da criativa apropriação do texto de Brontë, é revelar a dualidade das personagens em sua cumplicidade e resistência ao projeto imperialista que traz no bojo as não menos complexas relaçóes de gênero. 


\title{
GENDER, IDENTITY AND POWER: A REFLECTION ON WIDE SARGASSO SEA, BY JEAN RHYS
}

\begin{abstract}
This work aims to analyze Jean Rhys's novel Wide Sargasso Sea in order to display the author's strategy to deconstruct Charlotte Brontë's eurocentric discourse in Jane Eyre, granting voice to the colonized subject, besides allowing a "dive" into the web woven by patriarchy, getting men and women stuck in predetermined social roles.
\end{abstract}

KEYWORDS: gender, identity, patriarchy.

Recebido em: 19/03/12

Aprovado em: 26/11/12 